\title{
FORMATION OF INTERNATIONAL PROJECTS VALUES TO ACHIEVE TEAM SUCCESS IN PUBLIC-PRIVATE PARTNERSHIP
}

\author{
I. Kosach ${ }^{1}$, M. Dorosh ${ }^{2}$ \\ DOI: http://doi.org/10.15350/L_26/8/18/18
}

Abstract

The rapid changes occurring today in Ukraine led to a reappraisal of all social and economic groups and on a personal level. This leads to significant changes in behavior strategies entities in all areas of economic, social and political life that creates the need for enhanced existing and created new methods and approaches to decision-making to ensure effective cooperation project participants. These changes are related to PPP`s projects too. An important question is the definition and formation of a set of values of all project stakeholders to minimize the likelihood of conflicts of interest and ensure successful implementation. The proposed model of the article in the value system of the international project represents cyber process definitions, conversion and changes in the value of the project is the basis for an effective monitoring system convergence values of stakeholders.

Keywords: values, international projects, system.

Глобализация экономики привела к резкому росту разнообразных международных проектов, которые стирают границы между странами. В соответствии с реалиями экономики знаний в промышленно развитых странах ставка в современном управлении делается не на конкуренцию, а на сотрудничество как основу развития бизнеса. При этом ключевыми элементами сотрудничества выступают модели государственно-частного партнерства, которые позволяют объединить инвестиционную активность государства и частного капитала.

Термин "государственно-частное партнерство" является устойчивым переводом с английского языка "public-private partnership", но наиболее точно отражающим сущность данного вида отношений бизнеса и государства является понятие “публично-частное партнерство" (ПЧП), поскольку в качестве публичного партнера в часто выступают не только органы государственной власти, а и органы местного самоуправления, благотворительные фонды и общественные организации. Согласно определения Всемирного банка, публично-частное партнерство - это «...соглашение между публичной и частной сторонами по поводу производства и предоставления инфраструктурных услуг, заключаемое с целью привлечения

${ }^{1}$ Irina Kosach, Candidate of Economic Sciences, Associate Professor of Chernihiv National University of Technology, Ukraine.

2Mariia Dorosh, Candidate of Technical Sciences, Associate Professor of Chernihiv National University of Technology, Ukraine. 
дополнительных инвестиций и являющееся средством повышения эффективности бюджетного финансирования» [1].

Межкультурные различия для международных проектов ПЧП могут оказаться одним из главных факторов, определяющих их успех или провал с учетом того, что они требуют от менеджера особой осведомленности и щепетильности для установления доверия, которое является основой их успешной реализации [2]. В свою очередь, доверие формируется на основе единых ценностей всех заинтересованных лиц.

Впервые в истории философии к проблеме ценностей обратился Аристотель. По его мнению, основополагающим понятием, которое обуславливает существование человеческих представлений о "желаемое" и "должное", есть понятие "благо". Благом "называют или то, что является лучшим для каждого сущего..., или то, что делает благами другие причастные к нему вещи, то есть идею блага» [3].

Основной формой, в которой функционируют ценности, есть идеалы - представление о чем-то несуществующем, мнимое, совершенное, желательное. В смысле идеалов проявляются такие особенности ценностей, как надежды, надежды на лучшее будущее, ожидания желаемого. Таковы идеалы всесторонне развитой личности или общества, в котором будут удовлетворены все разумные потребности человека. Идеалы, как ценностные установки выполняют функцию духовных и социальных ориентиров, побуждений к практической деятельности человека, направленной на "приближение" будущего. Ценностное проектирование человеком своих жизненных устремлений в желаемое будущее, учение о формах и способах этого планирования является одним из основных назначений аксиологии. Среди всех ценностных механизмов человека аксиологи выделяют волю проявление желания человека осуществить свою целенаправленную, ценностно- определенную деятельность, направленную на достижение собственных целей.

В проектной среде именно система ценностей закладывает определенный образец поведения. Ценностные ориентиры всегда являются проявлением наиболее высокого уровня социальной регуляции и базисом эффективного функционирования общественных институтов. Формирование системы ценностей - это длительный процесс, который находится под влиянием многих факторов внешней среды, общественных взаимосвязей. Внешним окружением международных проектов является предпринимательская среда, фундаментом формирования которой являются социально-экономическая политика властей (внешний фактор) и экономикогеографическая характеристика территории (внутренний фактор).

Понимание системы ценностей отдельными стейхолдерами или командой проекта лежит в основе формирования эффективной структуры управления проектом публично-частного партнерства. Каждый участник проекта, с одной стороны, желает получить запланированный экономический результат любой ценой, что является отражением конфликта между духовностью и прагматизмом. В этом проявляется так называемый принцип утилитаризма, в основе которого - подчинение действий и поведения максимизации удовольствия и полезности, что понимается исключи- 
тельно в персонализированном контексте. С другой стороны, злоупотребление этим принципом приводит к преобладанию менталитета потребления над менталитетом производства. На этом акцентировал внимание $\mathrm{H}$. Бердяев, делая ударение на том, что «...в условиях преобладания идеалов потребления над идеалами производства происходит пренебрежение долга и дисциплины труда» [4]. Это может лежать в основе различий при определении понятия и восприятия ценностей участниками проекта из разных стран для формирования менеджером проекта целостной системы ценностей проекта.

Таким образом, успешное управление международными проектами в современных условиях возможно только благодаря взаимодействию принципов «экономизма» с ценностями гуманизма и достижения участниками проекта высокого культурного и духовного уровня развития. Наиболее удачное проявление всех ценностных ориентаций в проекте зависит от интеллектуальных способностей участников и представителей органов власти, а также от желания понять и найти точки соприкосновения (конвергенции) своих ценностей для обеспечения эффективного взаимодействия.

В международных проектах публично-частного партнерства следует четко разделять частные и государственные интересы. Представителем государственных интересов выступают местные органы исполнительной и законодательной власти, частные интересы присущи как физическим лицам, так и коммерческим и некоммерческим организациям разных форм собственности. Система ценностей формируется под воздействием общественного развития и потребностей различного уровня в зависимости от субъектов. В то же время, присутствует постоянная взаимосвязь между общественными потребностями и частными интересами субъектов, что необходимо учитывать при формировании систем ценностей участниковпредпринимателей. При этом, взаимодействие стейкхолдеров проекта направлено на выявление точек пересечения этих интересов и дает вектор развития процесса управления проектом. Далее, его эффективная реализация требует формирования комплекса определенных условий.

Актуальность применения системного подхода к решению проблем формирования и трансформации ценностей при реализации проекта предусматривает выделение отдельных форм и уровней. Д.А. Леонтьев применяет многоуровневый подход к рассмотрению ценностей. Первый уровень определяет ценности как общественные идеалы, выработанные общественным сознанием. Второй уровень характеризуется воплощением конкретных идеалов в действиях и поступках людей. Третий уровень рассматривает ценности как мотивационные структуры личности, которые побуждают ее к предметному воплощению в своей деятельности общественных ценностных идеалов [5]. Эти модели функционируют во взаимосвязи между собой, видоизменяясь и переходя одна в другую.

Определенный вид поведения конкретного участника проекта зависит от личных качеств и свойств, формирующих интерес и конкретную потребность, переходящие в мотив и целевую установку. В то же время этот процесс происходит в соответствии с системой ценностей, формирующей 
мотивы поведения, определяющей ориентиры предпринимательской деятельности экономического субъекта.

Таким образом, формирование определенной системы ценностей в проектах является одним из способов достижения успеха его реализации, а результат сформированной системы ценностей напрямую зависит от административных, институциональных и экономических условий для реализации международных проектов. Именно поэтому особую актуальность приобретает устранение административных барьеров, препятствующих организации и реализации международных проектов, активизации инвестиционной деятельности и инновационного развития. На первый план выходят вопросы доступности финансовых ресурсов, государственных гарантий, нормативно-правого обеспечения таких проектов.

В результате формирования и изложения ценностей участников проекта друг другу, на основе взаимного доверия, возникает эффект синергии. К этому групповому эффекту стремятся все менеджеры проекта для обеспечения получения ожидаемых ценностей всеми участниками проекта. В свою очередь, доверие между участниками становится возможным именно тогда, когда сформировано ядро из ценностей, понимаемых, принимаемых и разделяемых всеми членами группы. Тогда ценности выступают мощным интегративным мировоззренческим фундаментом мышления, поведения и деятельности каждого отдельного участника в проектной команде

Таким образом, на современном этапе развития проектной деятельности основным фактором успеха проекта является активное участие заинтересованных сторон в согласовании и принятии ключевых решений при реализации проекта. При этом каждая заинтересованная сторона, так же как и команда проекта, является выразителем различных ценностей, которые определяют различные цели и результаты реализации проекта. Также, в течение жизненного цикла проекта проявляется турбулентность и миграция ценностей заинтересованных сторон, а решения в проектных ситуациях необходимо принимать на основе показателей проекта, которые должны отражать гармонизированную ценность всех заинтересованных сторон проекта.

В международных проектах публично-частного партнерства ценности можно рассматривать в трех категориях:

1. Ценности, которые вносят в проект его участники (компетентность, опыт, инвестиции).

2. Ценности самого проекта, которые формируются из совокупности ценностей участников проекта с учетом синергетического эффекта.

3. Ценности, которые получают участники и потребители проекта от его реализации.

Эти категории формируют общую систему ценностей проекта. Для международных проектов такая система может быть представлена в виде таблицы 1. 
Основные ценности стейкхолдеров при реализации международных проектов

\begin{tabular}{|c|c|c|c|c|c|}
\hline $\begin{array}{c}\text { Ценности } \\
\text { государства } \\
\left(\mathrm{V}^{g}\right)\end{array}$ & $\begin{array}{c}\text { Ценности ор- } \\
\text { ганизаций } \\
\left(V^{e}\right)\end{array}$ & $\begin{array}{c}\text { Ценности } \\
\text { международ- } \\
\text { ных организа- } \\
\text { ций } \\
\left(V^{i o}\right)\end{array}$ & $\begin{array}{c}\text { Ценности } \\
\text { международ- } \\
\text { ных фондов } \\
\left(V^{i f}\right)\end{array}$ & $\begin{array}{c}\text { Ценности науч- } \\
\text { ных учрежде- } \\
\text { ний } \\
\left(V^{s}\right)\end{array}$ & $\begin{array}{c}\text { Ценности } \\
\text { иностран- } \\
\text { ных научных } \\
\text { учреждений } \\
\text { и организа- } \\
\text { ций } \\
\left(V^{i s}\right)\end{array}$ \\
\hline 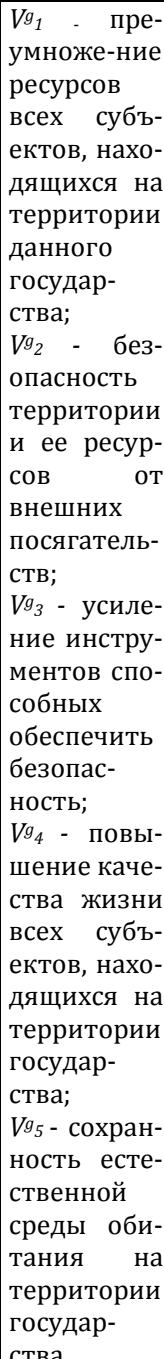 & $\begin{array}{l}e_{1} \text { - ценно- } \\
\text { сти, ради ко- } \\
\text { торых была } \\
\text { создана орга- } \\
\text { низация; } \\
V^{e_{2}} \text { - рост во } \\
\text { времени всех } \\
\text { видов ресур- } \\
\text { сов, находя- } \\
\text { щихся под } \\
\text { контролем } \\
\text { организа- } \\
\text { ции; } \\
V e_{3}-\text { защита } \\
\text { своего разви- } \\
\text { тия в усло- } \\
\text { виях конку- } \\
\text { рентной эко- } \\
\text { номической } \\
\text { среды; } \\
V^{e}{ }_{4}-\text { желание } \\
\text { обрести ло- } \\
\text { яльность со } \\
\text { стороны по- } \\
\text { требителей, } \\
\text { государства } \\
\text { и в целом че- } \\
\text { ловечества. }\end{array}$ & 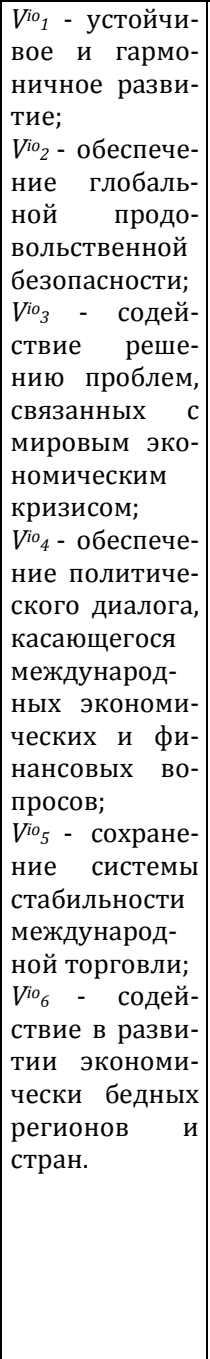 & 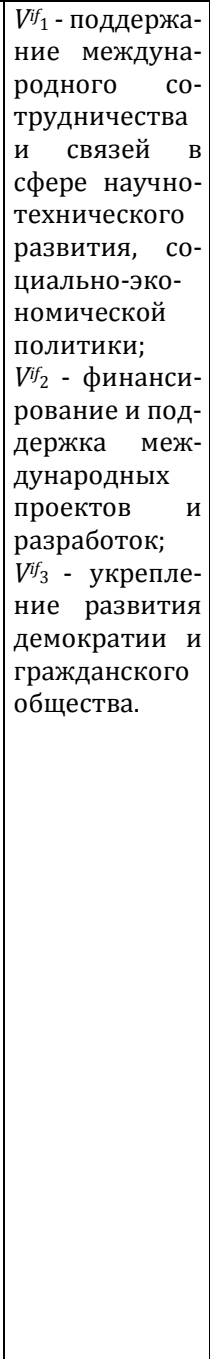 & 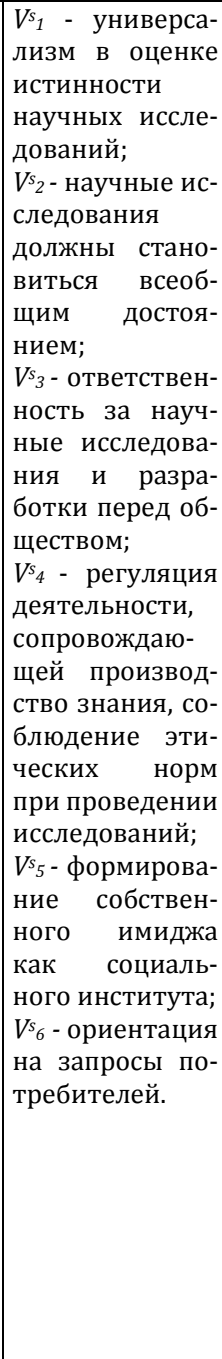 & $\begin{array}{l}V \text { Vis }_{1} \text { - органи- } \\
\text { зация ком- } \\
\text { муникаци- } \\
\text { онного про- } \\
\text { цесса между } \\
\text { научными } \\
\text { организаци- } \\
\text { ями в разных } \\
\text { странах; } \\
\text { Vis }- \text { коопера- } \\
\text { ция труда } \\
\text { ученых раз- } \\
\text { ных стран; } \\
\text { Vis - стремле- } \\
\text { ние к инте- } \\
\text { грации науч- } \\
\text { ных инфор- } \\
\text { мацион-ных } \\
\text { потоков в в } \\
\text { единую си- } \\
\text { стему зна- } \\
\text { ния. }\end{array}$ \\
\hline
\end{tabular}


Система ценностей проекта формируется на пересечении множеств ценностей стейкхолдеров проекта, которые определяют единство в стремлении эффективной реализации проекта:

$$
V_{p}=V^{g} \cap V^{e} \cap V^{i o} \cap V^{i f} \cap V^{s} \cap V^{i s}
$$

где:

$$
\begin{gathered}
V^{g}=\left\langle V_{1}^{g}, V_{2}^{g}, V_{3}^{g}, V_{4}^{g}, V_{5}^{g}\right\rangle ; V^{e}=\left\langle V_{1}^{e}, V_{2}^{e}, V_{3}^{e}, V_{4}^{e}\right\rangle ; \\
V^{i o}=\left\langle V_{1}^{i o}, V_{2}^{i o}, V_{3}^{i o}, V_{4}^{i o}, V_{5}^{i o} V_{6}^{i o}\right\rangle ; V^{i f}=\left\langle V_{1}^{i f}, V_{2}^{i f}, V_{3}^{i f}\right\rangle ; \\
V^{s}=\left\langle V_{1}^{s}, V_{2}^{s}, V_{3}^{s}, V_{4}^{s}, V_{5}^{s} V_{6}^{s}\right\rangle ; V^{i s}=\left\langle V_{1}^{i s}, V_{2}^{i s}, V_{3}^{i s}\right\rangle .
\end{gathered}
$$

Данная система образует ядро проекта. Формирование такого ядра может происходить только при активном участии руководителя проекта, поскольку далеко не все участники могут четко сформировать перечень ценностей организации, а участие в проекте может вызвать создание новых ценностей, о существовании которых руководители организацийучастников могут вообще не знать.

Таким образом, формирование системы ценностей проекта публично-частного партнерства требует активного участия руководителя для обеспечения эффективного взаимодействия всех участников проекта. Особенно это касается международных проектов, которые имеют максимальное количество разногласий при оценке ценностей из-за, иногда, совершенно разных культурных, политических, социальных и других условий их деятельности.

References

[1] Delmon J. Private Sector Investment in Infrastructure: Project Finance, PPP Projects and Risk. The World Bank and Kluwer Law International. 2009. P. 7.

[2] 2.Электронный pecypc: http://900igr.net/prezentatsii/ekonomika/Podgotovkaproekta/052-Mezhdunarodnye-proekty.html.

[3] Аристотель. Сочинения: В 4-х т. Т. 4 / Пер. с древнегреч.; Общ. ред. А. И. Доватура. - М.: Мысль, 1983.- 830 с.

[4] Бердяев Н. Философия неравенства/Н.Бердяев - М: АСТ, 2006.-352 с.

[5] Леонтьев Д.А. Ценность как междисциплинарное понятие: опыт многомерной реконструкции// Вопросы философии-1996 г.-№ 4. с.15-26. 